\title{
Reversal of Subgingival pH by Ascorbic Acid: A Weapon against Periopathogens
}

\author{
${ }^{1}$ Nitin H Dani, ${ }^{2}$ Chaitanya Pradeep Joshi, ${ }^{3}$ Vaibhavi H Bhatt, ${ }^{4}$ Dinkar P Khanna, ${ }^{5}$ Smita U Khedkar
}

\begin{abstract}
Background: Periodontal pocket is a dynamic environment. Several interacting factors within this microenvironment play an important role in initiation and progression of periodontal diseases. Power of hydrogen $(\mathrm{pH})$ is one of the important governing factor. Evidence suggests that $\mathrm{pH}$ of healthy gingival sulcus is between mildly acidic to neutral. A shift toward alkaline $\mathrm{pH}$ is observed in periodontal pocket which favors growth of gram-negative periopathogenic bacteria. Thus, the aim of the current study is to assess possible role of ascorbic acid in reversing subgingival alkaline $\mathrm{pH}$ and to determine optimum concentration of ascorbic acid for bacteriocidal effects.
\end{abstract}

Materials and methods: Subgingival plaque samples from 37 generalized chronic periodontitis patients were collected. Growth inhibition of periodontal pathogens with four different concentrations of ascorbic acid was examined anerobically after 48 hours. Photometric analysis and disk diffusion method were employed to quantify inhibitory effects.

Results: Evidence obtained by both the methods demonstrated possible bactericidal activity of ascorbic acid at $5 \mathrm{mg} / \mathrm{ml}$. At this concentration, ascorbic acid showed stronger $\mathrm{pH}$ dependent inhibition toward gram-negative periopathogens.

Conclusion: Ascorbic acid can inhibit growth of periodontal pathogens at high concentration. Subgingival vitamin $C$ administration could lead to prevention of plaque induced diseases. Due to its acidic nature, it should be used cautiously around teeth but recommended for maintenance of implants.

Keywords: Ascorbic acid, Chronic periodontitis, Antiplaque agent.

How to cite this article: Dani NH, Joshi CP, Bhatt $\mathrm{VH}$, Khanna DP, Khedkar SU. Reversal of Subgingival pH by Ascorbic Acid: A Weapon against Periopathogens. Int $\mathrm{J}$ Oral Implantol Clin Res 2014;5(3):99-104.

Source of support: Nil

Conflict of interest: None

\section{INTRODUCTION}

The composition of the subgingival microbiota is determined by a variety of factors within the dynamic microenvironment of periodontal pocket. Interacting bacteria, host related

${ }^{1}$ Professor, ${ }^{2-4}$ Postgraduate Student, ${ }^{5}$ Professor and Head

${ }^{1-5}$ Department of Periodontics, MGV's KBH Dental College and Hospital, Nashik, Maharashtra, India

Corresponding Author: Chaitanya Pradeep Joshi, Postgraduate Student, Department of Periodontics, MGV's KBH Dental College and Hospital, Nashik, Maharashtra, India, Phone: 02352370431 e-mail: chaitanya.joshi87@gmail.com factors and the environmental factors govern the growth of pathogenic bacteria (Fig. 1). Power of hydrogen $(\mathrm{pH})$ of gingival crevice is one of the crucial environmental factors. In health, it is about 6.7 which shifts toward alkaline in the periodontally diseased condition. ${ }^{1}$ This alkaline $\mathrm{pH}$ of periodontal pocket aids pathogenic bacteria to thrive and multiply. ${ }^{2}$ Severity of periodontitis is characterized by increased in attachment loss owing to progressive deepening of periodontal pocket depth. Power of hydrogen of periodontal pocket and especially the gingival crevicular fluid (GCF), is characterized by alkaline $\mathrm{pH}$, which may rise above 8.5.,4 Ability of some periodontal pathogens like Porphyromonas gingivalis, Prevatella intermedia and Fusobacterium nucleatum to ferment amino acids leads to an elevated subgingival $\mathrm{pH}^{5,6}$ This locally alkalified microenvironment aids in accelerating growth of these secondary colonizers. An alkaline $\mathrm{pH}$ of 8.2 increases cell surface hydrophobicity as well as induces the coadhesion and biofilm formation of F. nucleatum, ${ }^{7}$ which is considered a 'bridging' organism between early and late colonizers within the plaque biofilm. Moreover, an accelerated expression of various virulence factors of these periopathogens arms them against host's immune response. ${ }^{8}$

Based on above observations, we hypothesized that introduction of organic acid can reverse this increase in $\mathrm{pH}$ and in turn substantially inhibit growth of periopathogens. To test this theory, ascorbic acid was a preferred choice due to its proven benefits in the field of periodontics and allied medical sciences..$^{9,10}$

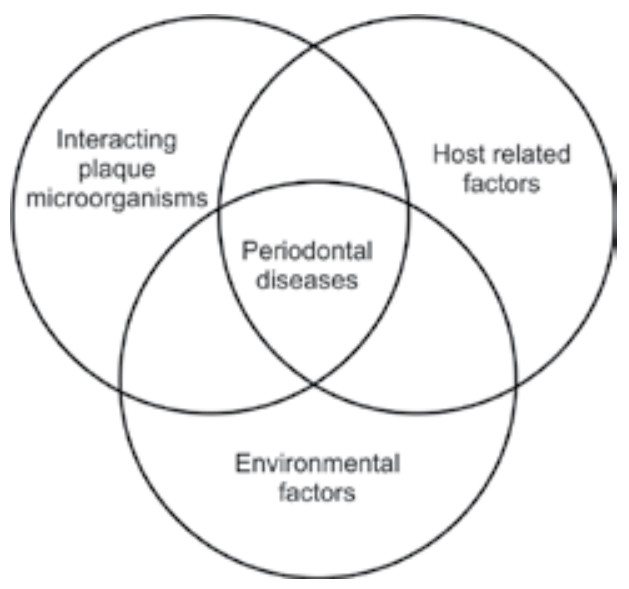

Fig. 1: Interacting role of pathogens, host and environmental factors in development of periodontal disease 
Ascorbic acid also known as $\mathrm{AscH}_{2}$, ascorbate or vitamin $\mathrm{C}$ is a water-soluble ketolactone with two ionisable hydroxyl groups. Humans cannot synthesize ascorbic acid, hence they have to depend on dietary ascorbic acid. World Health Organization (WHO) recommends minimum dietary allowance of ascorbic acid around $45 \mathrm{mg}$ per day/300 mg per week. ${ }^{11}$

Being efficient antioxidant, ascorbic acid reacts with aqueous peroxyl radicals. It also acts indirectly by restoring the antioxidant properties of fat-soluble vitamin E. Overall as an antioxidant, it scavenges free oxygen radicals and thus controls lipid peroxidation of cellular membranes including those surrounding as well as within intracellular organelles. Additionally, ascorbic acid is an integral component for synthesis and turnover of collagen which is a backbone of periodontal apparatus. ${ }^{12}$

Thus, the aim of this study was to investigate whether reversing alkaline $\mathrm{pH}$ can lead to inhibition of periopathogens and to determine optimum concentration of ascorbic acid for its bactericidal activity.

\section{MATERIALS AND METHODS}

\section{Participant Selection and Sample Collection}

Patients who reported to the Department of Periodontics at MGV's KBH Dental College and Hospital, Nashik from June 2014 to July 2014 were screened. Thirty-seven patients those were diagnosed with generalized chronic periodontitis having at least 3 sites with probing depth $\geq 6 \mathrm{~mm}$. The patients were well informed of the study protocol and objectives before participation. The patients were included if they fulfilled the following inclusion criteria: (1) No current use of antibiotics and multivitamin supplements or history of such usage for last 3 months, (2) no antiseptic mouthrinse usage; professional dental cleaning or periodontal treatment within 6 months of sample collection, (3) otherwise systemically healthy, (4) no pregnancy and (5) no smoking.

Subgingival plaque samples were collected by single calibrated examiner (CJ). Three sites with probing depth $\geq 6 \mathrm{~mm}$ per patient were selected for sample collection. These sites were thoroughly isolated with cotton rolls and supragingival deposits were scaled with a sterile curette. ${ }^{\mathscr{C}}$ Number 30 sterile paper point ${ }^{\S}$ was inserted into the apex of each periodontal pocket and kept for approximately $20 \mathrm{sec}-$ onds. ${ }^{13}$ Upon removal, paper points from each patient were pooled in a single test tube containing Robertson's cooked meat media (RCM) for transportation to the department of microbiology. Same protocol was repeated for each patient.
Patients' samples were grown in RCM for 4 to 6 hours in an incubator at $37^{\circ} \mathrm{C}$. Development of turbidity confirmed their viability.

\section{Preparation and Dilution of Ascorbic Acid}

Five hundred milligrams of ascorbic acid ${ }^{\ddagger}$ was dissolved in $10 \mathrm{ml}$ of brain-heart infusion (BHI) ${ }^{\#}$ broth to get a stock solution of $50 \mathrm{mg} / \mathrm{ml}$. Final concentrations of 5, 2.5, 1 and $0.5 \mathrm{mg} / \mathrm{ml}$ were obtained using BHI broth. Solutions were freshly prepared at the time of experimentation.

\section{Antimicrobial Activity of Ascorbic Acid}

\section{Colorimetric Analysis}

Bacterial sample from each patient was inoculated in four different test tubes containing $5 \mathrm{ml}$ of BHI broth having ascorbic acid at concentration $0.5,1,2.5$ and $5 \mathrm{mg} / \mathrm{ml}$. Procedure was repeated for each patient's sample. All these test tubes were incubated at $37^{\circ} \mathrm{C}$ in an anerobic chamber for 48 hours. Tests were performed in triplicates to assess veracity of the results. A test tube containing sterile BHI broth was used as a negative control. A test tube with BHI broth along with patient's plaque sample without ascorbic acid was used as positive control for each individual. Colorimeter* was calibrated using sterile BHI broth by setting it as zero optical density (OD). After incubation, growth of periopathogens was estimated by measurement of OD at $530 \mathrm{~nm}$ wavelength. Smears were prepared for each concentration and gram staining was performed.

\section{Agar Disk Diffusion Method}

Simultaneously, patient's sample was spread on a blood agar plate to obtain lawn culture. Four pre-sterilized nonimpregnated paper disks ${ }^{\sharp}$ were immersed in four different ascorbic acid concentrations $(5,2.5,1$ and $0.5 \mathrm{mg} / \mathrm{ml})$ and placed over these seeded blood agar plate. Metronidazole disk $^{\#}$ was placed to confirm presence of anerobic bacteria. Samples from all the patients were assessed in a similar fashion.

\section{Power of Hydrogen Analysis}

Power of hydrogen was checked for all four concentrations of ascorbic acid using a calibrated $\mathrm{pH}$ meter".

\section{Surface Roughness Analysis using Profilometer}

Acidic environment is known to cause surface roughness of tooth in the form of microabrasions and pitting. ${ }^{14}$ To verify this phenomenon an optimum concentration of ascorbic

\footnotetext{
"Gracey curettte, Hu-Friedy Mfg Co, LLC, Chicago, USA; §Sure Dent Corporation, Gyeonggi-do, Republic of Korea; \#HiMedia Laboratories Pvt Ltd, Mumbai, India; ${ }^{\ddagger} H$ iMedia Laboratories Pvt Ltd, Mumbai, India; *HANS 251, Kanad Vidyut, Pune, India; ${ }^{\top} H I$ 3512, Hanna Instruments, Mumbai, India
} 
acid showing maximum bactericidal activity was selected. We subjected 15 extracted teeth and 15 implants $^{\phi}$ to $5 \mathrm{mg} /$ $\mathrm{ml}$ solution of ascorbic acid. The teeth and implant samples were immersed in the solution of ascorbic acid $(5 \mathrm{mg} / \mathrm{ml})$. Surface roughness was recorded at baseline (day 0 ) and after $3,7,15$ and 30 days of incubation using a profilometer ${ }^{\sharp}$.

\section{RESULTS}

\section{Antimicrobial Activity of Ascorbic Acid}

\section{Colorimetric Analysis}

Optical density value of broth culture is directly proportional to growth of an organism. It is a method routinely used to estimate bacterial growth. The results showed that ascorbic acid is capable of inhibiting the growth of periopathogens in a concentration dependent manner. Five milligram per milliliter of ascorbic acid demonstrated maximum inhibitory effect as mean $\mathrm{OD}$ value $(0.05)$ was very close to 0 (sterile BHI broth). When mean OD value of positive control (without ascorbic acid) is compared with mean OD value of $5 \mathrm{mg} / \mathrm{ml}$ concentration, it showed stronger inhibition of periopathogenic bacteria (Graph 1).

Microbial analysis confirms the above observations. Microscopy reveals that there is a progressive reduction in gram-negative bacteria from 0.5 to $5 \mathrm{mg} / \mathrm{ml}$ concentration of ascorbic acid. A pronounced bactericidal activity was concluded from absence of gram-negative rod-shaped periopathogenic bacteria at $5 \mathrm{mg} / \mathrm{ml}$ concentration of ascorbic acid (Figs 2A to E).

\section{Agar Disk Diffusion Method}

A clear zone of inhibition around metronidazole disk signifies the presence of anerobic organisms in the collected samples. Five milligram per milliliter concentration of ascorbic acid consistently exhibited well-demarcated zone of inhibition followed by $2.5 \mathrm{mg} / \mathrm{ml}$ concentration (Fig. 3). A mean inhibition zone for $5 \mathrm{mg} / \mathrm{ml}$ concentration was $9.58 \pm 0.007 \mathrm{~mm}$, whereas for $2.5 \mathrm{mg} / \mathrm{ml}$ concentration, it was $6.25 \pm 0.009 \mathrm{~mm}$

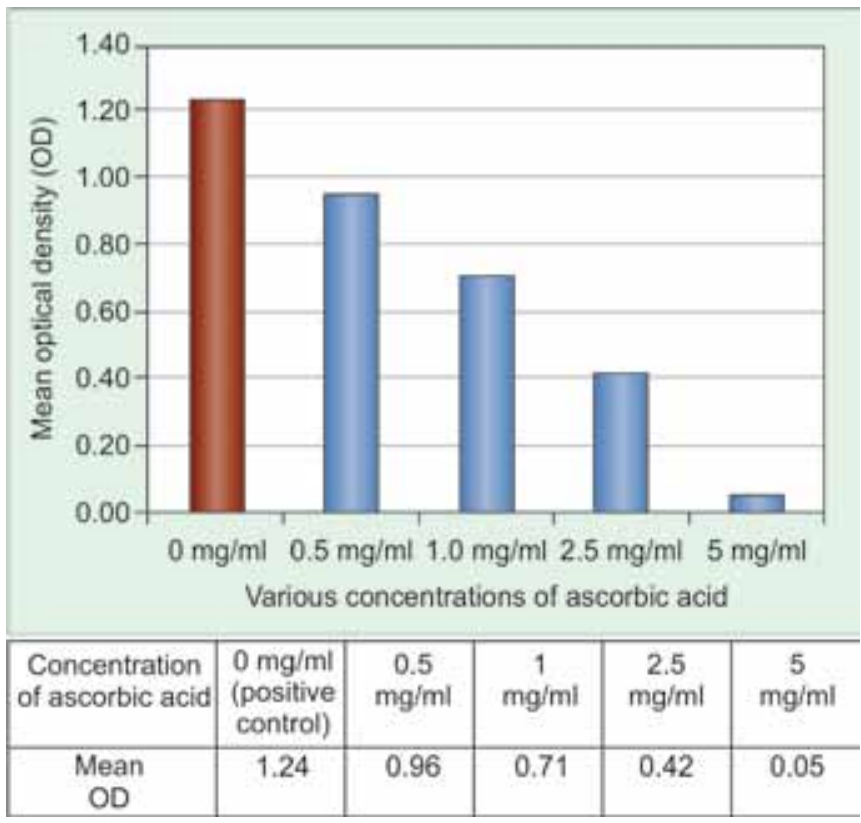

Graph 1: Mean optical density values of BHI broth culture with various concentrations of ascorbic acid

(Graph 2). These results indicate a 1.5 times stronger inhibition of periopathogens for $5 \mathrm{mg} / \mathrm{ml}$ concentration when compared with of $2.5 \mathrm{mg} / \mathrm{ml}$ concentration. In few of the tested samples, $1 \mathrm{mg} / \mathrm{ml}$ concentration showed negligible zone of inhibition hence excluded from statistical analysis.

\section{Power of Hydrogen Analysis}

Power of hydrogen of medium changes from 6.8 to 3.2 at increasing concentrations of ascorbic acid (Graph 3). This drop in $\mathrm{pH}$ can be related to decreased growth of peripathogens in dose dependent manner.

\section{Surface Analysis using Profilometer}

Five milligram per milliliter concentration of ascorbic acid showed maximum inhibition toward periopathogens. However, due to increased acidity, possible surface erosion on tooth was expected. Data revealed decreased $\mathrm{pH}$ caused surface changes on the tooth. Mean baseline Rz value for teeth was $34.78 \mu \mathrm{m}$ which changed to $35.58 \mu \mathrm{m}$ after 3 days.
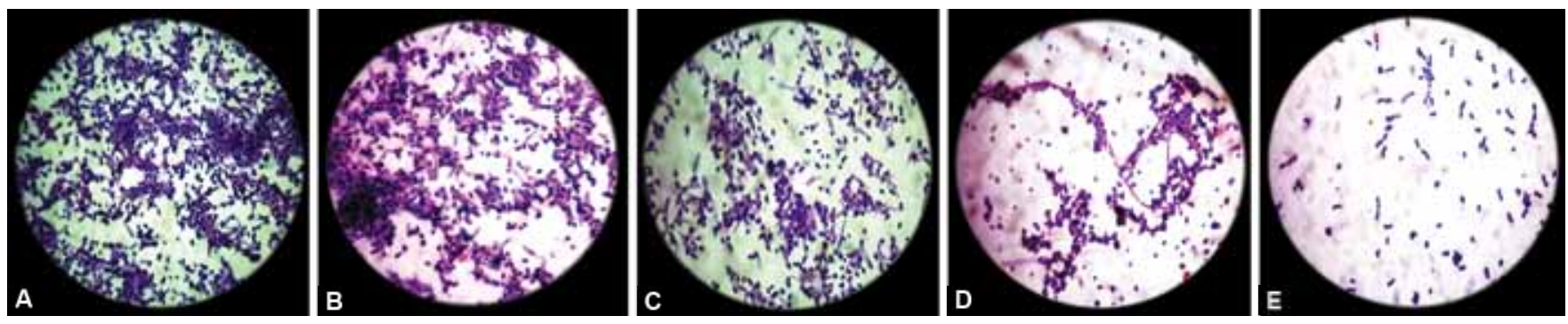

Figs 2A to E: Progressive reduction in number of gram-negative rod shaped bacteria at increasing concentration of ascorbic acid: (A) Positive control (without ascorbic acid), (B) $0.5 \mathrm{mg} / \mathrm{ml}$, (C) $1 \mathrm{mg} / \mathrm{ml}$, (D) $2.5 \mathrm{mg} / \mathrm{ml}$ and (E) $5 \mathrm{mg} / \mathrm{ml}$

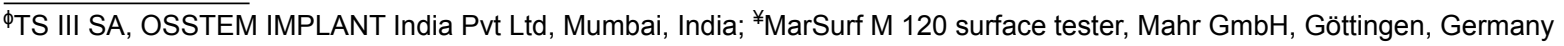




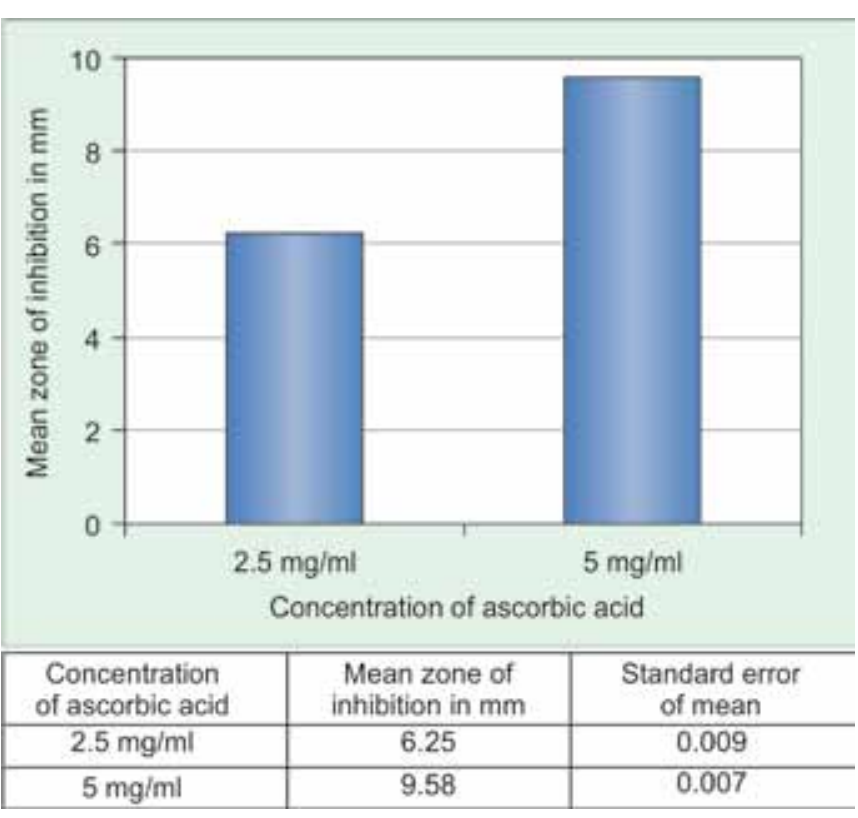

Graph 2: Mean zone of inhibition in millimeters with $5 \mathrm{mg} / \mathrm{ml}$ and $2.5 \mathrm{mg} / \mathrm{ml}$ concentration of ascorbic acid using disk diffusion method

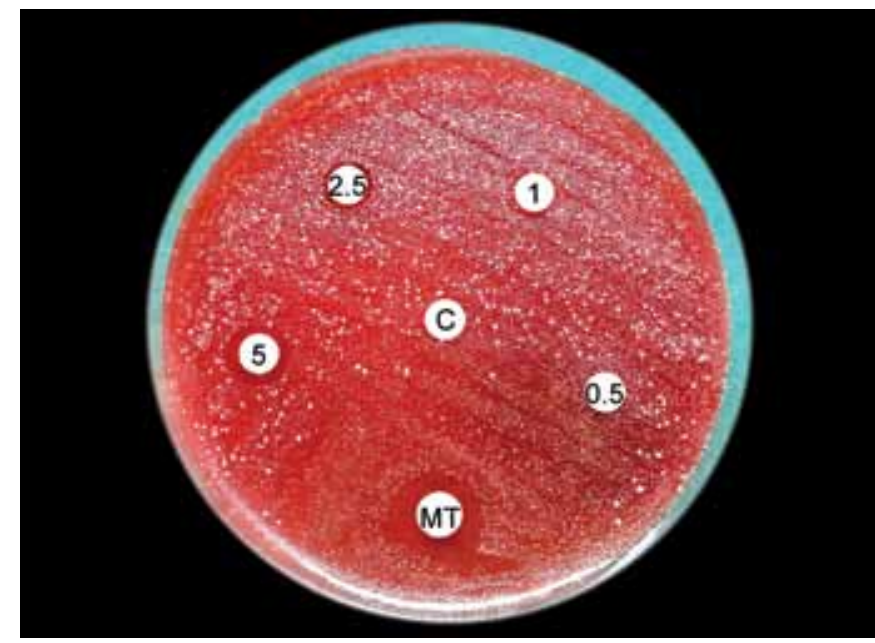

Fig. 3: Growth inhibition of periodontopathogens by disk diffusion method. Number over the disk indicates concentration of ascorbic acid in $\mathrm{mg} / \mathrm{ml}$. MT: Metronidazole; C: Control (without ascorbic acid)

This change in mean $\mathrm{Rz}$ value was minimal after 3rd day which increased progressively after 7,15 and 30th day of exposure to ascorbic acid.

On the contrary, implants being composed of inert material like titanium showed negligible change in surface roughness values at $3 \mathrm{rd}, 7,15$ and 30th day respectively. Mean baseline Rz value for implants was $0.73 \mu \mathrm{m}$ (Graph 4).

\section{DISCUSSION}

Periodontitis is multibacterial infection commonly associated with the proliferation of the gram-negative anerobic pathogenic bacteria. ${ }^{16}$ Such organisms though low in numbers, are normal inhabitant of healthy subgingival sites. However, certain allogenic factors activate and accelerate

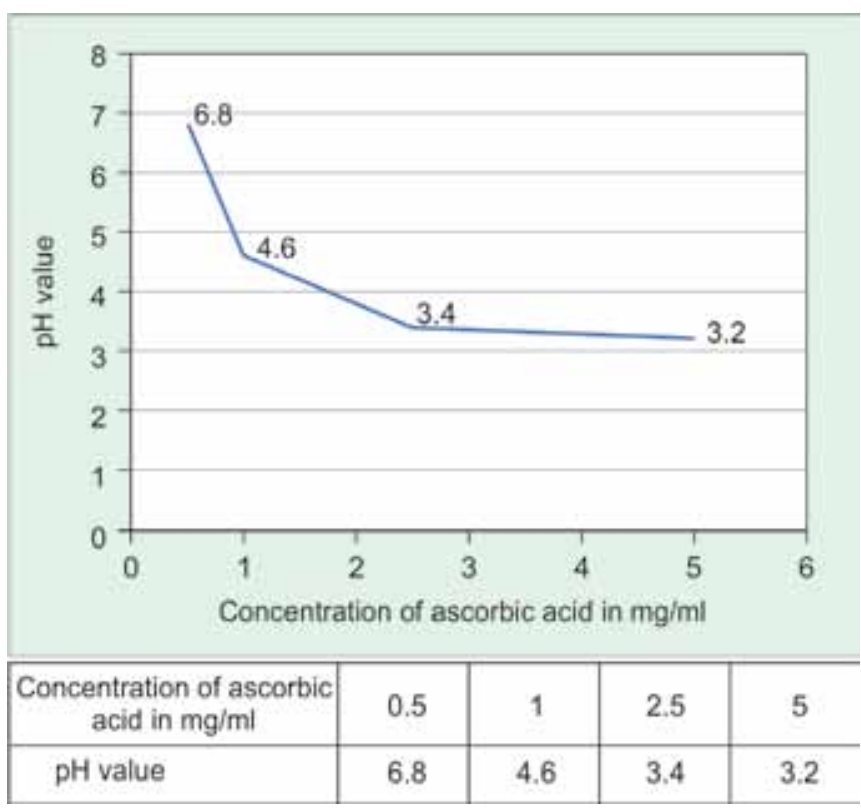

Graph 3: Power of hydrogen values of different concentration of ascorbic acid used in the experiment

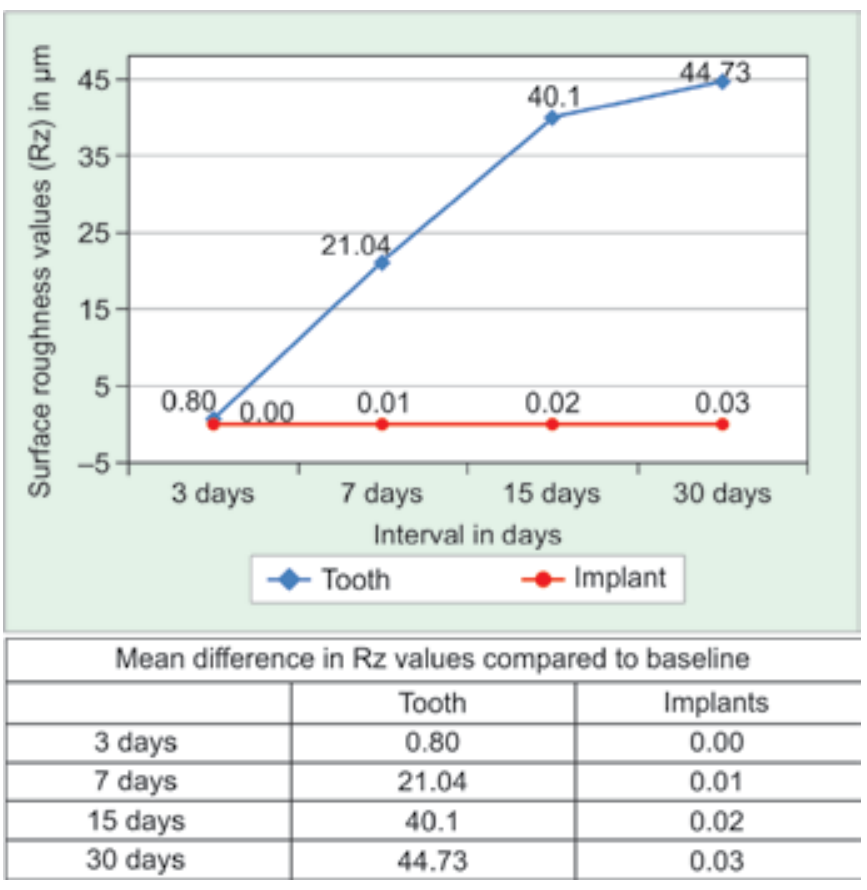

Graph 4: Mean difference in surface roughness values of tooth as well as implant measured at specific intervals in presence of acidic environment

their proportions during the transition from health to disease. Environmental factors like alkaline $\mathrm{pH}$ of the diseased gingival sulcus in particular is conducive for proliferation of 'red complex' bacteria. ${ }^{6,15}$

Bickel and Cimasoni showed that the $\mathrm{pH}$ in periodontal pockets rage from 6.9 to as high as $8.66 .^{3}$ This was also confirmed by Eggert et al who reported that $7 \%$ of subjects with periodontal disease had sites measuring $\mathrm{pH} 7.6$ or higher. ${ }^{4}$ Being asaccharolytic, gram-negative periodontopathogenic bacteria, such as $P$. gingivalis, F. nucleatum and 
$P$. intermedia utilize proteins and amino acids as their energy source. Fermentation of these proteins and amino acids produce ammonia which induce subgingival environment to become basic. This activity may partly contribute to acid neutralizing activity of dental plaque and protect them from acid attack. ${ }^{6}$ A notion supported by the findings of Marsh et al who reported optimum growth $\mathrm{pH}$ for $P$. gingivalis to be 7.5 and Takahashi et al who stated that organism stops growing if $\mathrm{pH}$ drops below 6.5. Alkaline $\mathrm{pH}$ is also associated with an increased virulence activity of the organism. ${ }^{17,18}$ The optimal $\mathrm{pH}$ range for growth of $A$. actinomycetemcomitans and $P$. intermedia was reported between $\mathrm{pH} 7$ and 8. ${ }^{6,19}$

Power of hydrogen reversal by introduction of organic acid can control growth of periopathogenic bacteria. Based on colorimetric analysis and microbial analysis, we were able to validate this proposed hypothesis. Ascorbic acid (ascorbate or vitamin C) was a suitable choice as its intrinsic properties are beneficial in periodontics. Deficiency of dietary ascorbic acid can escalate the initial signs of an inflammatory response, such as gingival redness and swelling. ${ }^{20}$ Such changes are attributed to blood vessel damage caused by deficient collagen production and increased collagen degradation. Leggott et al and Chapple et al reported an inverse relationship between plasma ascorbic acid levels and the prevalence of periodontitis. ${ }^{9,21}$

An approximate peak plasma concentration of 0.01 $\mathrm{mg} / \mathrm{ml}$ is achieved after a systemic dose of 300 to $500 \mathrm{mg}$ ascorbic acid. ${ }^{22}$ This value is much lesser to have any bacteriocidal effects at periodontally involved sites.

Present study demonstrated a concentration dependent growth inhibition of periopathogens which was maximum at $5 \mathrm{mg} / \mathrm{ml}$. Isela et al reported final inhibitory concentration of ascorbic acid to be $20 \mathrm{mg} / \mathrm{ml}^{23}$ which was much higher than in the present study. Relevant data of $\mathrm{pH}$ values for the ascorbic acid concentrations used in their study and its effects on tooth surfaces is not reported. Present study evaluated the correlation between concentration dependent $\mathrm{pH}$ value of ascorbic acid and its effect on tooth as well as implant surfaces. Proposed concentration of $5 \mathrm{mg} / \mathrm{ml}$ has $\mathrm{pH}$ value 3.2. At this value, we observed progressive change in surface roughness of tooth which was most apparent after 7 th day. However, implants consistently showed no effects.

Thus, we propose the administration of ascorbic acid locally at $5 \mathrm{mg} / \mathrm{ml}$ to reverse alkaline $\mathrm{pH}$ of periodontal pockets and effectively reduce periopathogens. A suitable route of administration has to be designed for its prolonged presence at diseased sites.

\section{Limitations}

Isolation and identification of periodontopathogenic bacteria was not possible due to inaccessibility to such facility.
It is an in vitro study which is carried out in a static environment. Results might defer under dynamic oral conditions; as ascorbic acid is a water soluble vitamin.

\section{CONCLUSION}

This study provides evidence that reversal of alkaline $\mathrm{pH}$ of subgingival environment in disease can cause growth inhibition of gram-negative rod shaped periodontal pathogens. This can be achieved with organic acid like ascorbic acid at concentration $5 \mathrm{mg} / \mathrm{ml}$ in particular. Subgingival administration of ascorbic acid can lead to prevention of plaque induced diseases. As suggested by surface roughness analysis, it can be used cautiously around teeth, however, it is strongly recommended for maintenance of dental implants.

\section{REFERENCES}

1. Kobayashi K, Soeda W, Watanabé T. Gingival crevicular $\mathrm{pH}$ in experimental gingivitis and occlusal trauma in man. $\mathrm{J}$ Periodontol 1998;69(9):1036-1043.

2. Takahashi N. Microbial ecosystem in the oral cavity: metabolic diversity in an ecological niche and its relationship with oral diseases. Int Congr Ser 1284 2005:103-112.

3. Bickel M, Cimasoni G. The $\mathrm{pH}$ of human crevicular fluid measured by a new microanalytical technique. J Periodontal Res 1985;20(1):35-40.

4. Eggert FM, Drewell L, Bigelow JA, Speck JE, Goldner M. The $\mathrm{pH}$ of gingival crevices and periodontal pockets in children, teenagers and adults. Arch Oral Biol 1991;36(3):233-238.

5. Barker HA. Amino acid degradation by anaerobic bacteria. Annu Rev Biochem 1981;50:23-40.

6. Takahashi N. Acid-neutralizing activity during amino acid fermentation by Porphyromonas gingivalis, Prevotella intermedia and Fusobacterium nucleatum. Oral Microbiol Immunol 2003;18(2):109-113.

7. Zilm PS, Rogers AH. Co-adhesion and biofilm formation by Fusobacterium nucleatum in response to growth $\mathrm{pH}$. Anaerobe 2007;13(3-4):146-152.

8. Pöllänen MT, Annamari P, Ihalin R. Environmental stimuli shape biofilm formation and the virulence of periodontal pathogens. Int J Mol Sci 2013;14(8):17221-17237.

9. Leggott PJ, Robertson PB, Rothman DL, Murray PA, Jacob RA. The effect of controlled ascorbic acid depletion and supplementation on periodontal health. J Periodontol 1986; 57(8):480-485.

10. Ashor AW, Lara J, Mathers JC, Siervo M. Effect of vitamin $\mathrm{C}$ on endothelial function in health and disease: a systematic review and meta-analysis of randomised controlled trials. Atherosclerosis 2014;235(1):9-20.

11. World Health Organization (2004). 'Chapter 7: Vitamin C'. Vitamin and mineral requirements in human nutrition. 2nd ed. Geneva: World Health Organization. ISBN 92-4-154612-3.

12. Ishikawa S, Iwasaki K, Komaki M, Ishikawa I. Role of ascorbic acid in periodontal ligament cell differentiation. J Periodontol 2004;75(5):709-716.

13. Jervøe-Storm PM, Alahdab H, Koltzscher M, Rolf Fimmers, Søren Jepsen. Comparison of curet and paper point sampling of 
subgingival bacteria as analyzed by real-time polymerase chain reaction. J Periodontol 2007;78(5):909-917.

14. Prati C, Montebugnoli L, Suppa P, Valdrè G, Mongiorgi R. Permeability and morphology of dentin after erosion induced by acidic drinks. J Periodontol 2003;74(4):428-436.

15. Socransky SS, Haffajee AD. Periodontal microbial ecology. Periodontol 2000 2005;38(1):135-187.

16. Socransky SS, Haffajee AD, Cugini MA, Smith C, Kent RL. Microbial complexes in subgingival plaque. J Clin Periodontol 1998;25(2):134-144.

17. Marsh PD, McDermid AS, McKee AS, Baskerville A. The effect of growth rate and haemin on the virulence and proteolytic activity of porphyromonas gingivalis W50. Microbiology 1994;140(4):861-865.

18. Takahashi N, Sato T. Preferential utilization of dipeptides by porphyromonas gingivalis. J Dent Res 2001;80(5):1425-1429.
19. Sreenivasan PK, Meyer DH, Fives-Taylor PM. Factors influencing the growth and viability of actinobacillus actinomycetemcomitans. Oral Microbiol Immunol 1993;8(6):361-369.

20. Nakamoto T, McCroskey M, Mallek HM. The Role of ascorbic acid deficiency in human gingivitis: a new hypothesis. J Theor Biol 1984;108(2):163-171.

21. Chapple ILC, Milward MR, Dietrich T. The prevalence of inflammatory periodontitis is negatively associated with serum antioxidant concentrations. J Nutr 2007;137(3):657-664.

22. Padayatty SJ, Sun H, Wang Y, Riordan HD, Hewitt SM, Katz A, Wesley RA, Levine M. Vitamin C pharmacokinetics: implications for oral and intravenous use. Ann Intern Med 2004; 140(7):533-537.

23. Isela SNR, Sergio NC, José MSJ, Rene HD, Claudio CR. Ascorbic acid on oral microbial growth and biofilm formation. Pharma Innovation Journal 2013;2(4):103-109. 